\title{
The Role of Programming Experience in ICT Students' Learning Motivation and Academic Achievement
}

\author{
Külli Kori, Margus Pedaste, Äli Leijen, and Eno Tõnisson
}

\begin{abstract}
There is a high demand for qualified Information and Communication Technology (ICT) practitioners in the European labor market. However, a high dropout rate in higher education among ICT students is a big problem. One reason why students drop out is low study motivation, which in turn can influence the learning outcomes. Prior experience, such as learning ICT at the general education level and working in ICT field may influence their study motivation and learning outcomes at the higher education level and for this reason, the relationship between the above indicated variables was investigated in the current study. Data were collected in three higher education institutions in Estonia from 301 first-year ICT students. After the first semester, students filled in a questionnaire which contained the Academic Motivation Scale (AMS-C 28) College (CEGEP) version and questions about prior and current experience in ICT. The results show that the students who had learned programming before entering university had higher weighted average grades in the first semester and the students who started studying programming for the first time at university had more external regulation (a subcategory of extrinsic motivation) influencing their studies than other students. Working students had less motivation and lower results regarding the two subcategories of extrinsic motivation (introjected and external regulation). The findings show that learning programming before starting ICT studies gives an advantage in studies and working during studies is related to lower extrinsic motivation. This suggests improving students' opportunities for gaining experience in programming (studying or working) prior to university studies in order to support their future studies in the field of ICT.
\end{abstract}

Index Terms-Academic achievement, higher education, ICT studies, motivation, work experience.

\section{INTRODUCTION}

The role of Information and Communication Technology (ICT) has increased rapidly in recent years in all economic sectors. However, lack of labor with good ICT knowledge and skills is a worldwide problem. For example, in the European Union, the forecast in 2013 suggests that the unmet demand for ICT practitioners could rise to $372,000-864,000$ by 2015 and to $481,000-1,685,000$ by 2020 (according to different scenarios) [1]. Unfortunately, the number of computer science graduates in the European Union has been decreasing since 2006 [1]. In Estonia, the forecast suggests that by the year 2020, the number of higher education graduates needed in the ICT sector and other sectors of the economy will be between 6,661 and 8,456 [2]. If the number of ICT student

Manuscript received September 15, 2014; revised December 1, 2014.

The authors are with the University of Tartu, Ülikooli 18, Tartu 50090, Estonia (e-mail: kulli.kori@ut.ee, margus.pedaste@ut.ee, ali.leijen@ut.ee, eno.tonisson@ut.ee). positions in higher education does not change compared with the years 2010-2012, the number of ICT graduates will be around 8,400 by the year 2020 , which will probably meet the demand [2]. However, it is only the case if all students who start studies will finish them as well. Unfortunately, many students will drop out already in the first year of their studies. So the problem is not a low number of ICT students but a high dropout rate. Many of the students who drop out will still enter the labor market and, therefore, more and more ICT workers will not have a degree in ICT. However, the number of student candidates in ICT is about 2.6 times higher than the number of student positions [3]. It means that we have to understand which characteristics of the candidates should be taken into account, in order to avoid dropout. Previous experience with ICT either in studies or at work might be an important factor to consider [4].

Dropout in ICT related curricula is a problem in many countries. The average student dropout rate for computer science students in Europe is at around 19\% [1]. In Estonia, the dropout rate in ICT studies is around 40\%, which is much higher than the European average. ICT students' dropout is also a problem in Asia [5] and the United States [6]. One factor that may influence dropout in all disciplines is learning motivation [7], [8]. Learning motivation could be measured during student recruitment, so that candidates who are more likely to finish their studies will be accepted.

Learning motivation is a condition which activates behavior and gives it direction [9]. Motivation is one of the characteristics which influence how students approach their learning [10]. Motivation is important in academic achievement - higher motivation results in higher academic achievement [11]. Bruinsma [11] found that students who had higher motivation in terms of expectancy earned more credit points at the end of the first and the second study-year. Moreover, higher motivation can lower dropout rates [12]. For these reasons, it is important to find out which type of motivation ICT students have and how it might affect their learning outcomes and dropout.

According to the Self-Determination Theory [13], motivation can be divided based on the different reasons that give rise to an action. In general, motivation can be divided into intrinsic motivation and extrinsic motivation. Intrinsic motivation means that a person does something because it is inherently interesting or enjoyable, and extrinsic motivation means that a person does something because it leads to a separable outcome [13]. It has been found that intrinsic academic motivation correlates positively with school achievement [14]. Abar et al. [15] investigated high school students and found that the motivation type for attending school is associated with academic achievement and late high 
school dropout. Students with identified and introjected extrinsic motivation and students with external regulation were at the highest risk of dropping out of high school. One more motivation type can be added to intrinsic and extrinsic motivation - amotivation. Amotivation means that a person is lacking intention to act [16], which may cause dropout [7]. In this study, these three motivation types and their subcategories [17] are under investigation to find out which type of motivation is driving first-year ICT students.

During the first year, ICT students in Estonia and many other countries learn basic subjects, such as mathematics and programming, which are important in further ICT studies. Divjak et al. [18] showed that mathematics courses were difficult and an obstacle for retaining ICT students. In Croatia, $60.56 \%$ of ICT students passed the mathematics course in the academic year 2006-2007 [18]. Programming courses are also difficult for many students and, therefore, failure rates in such courses are quite high [19], [20]. Based on the systematic literature review of introductory programming, the mean worldwide pass rate in an introductory programming course is $67.7 \%$ [21]. This kind of difficult subjects may decrease students' motivation and may cause dropout. It has been found that if the workload in the introductory class is too heavy compared with the students' level of experience, students more likely will not continue the computer science major [22]. In Estonia, some ICT students have learned programming before they start studying ICT at the higher education level, but some have their first contact with programming at university. A similar situation can be found in other countries: in Taiwan, for instance, about $50 \%$ of the first-year computer science students have some programming experience [23]. Moreover, in Estonia, 14\% of the first-year ICT students had been working in the ICT field before they started studying ICT [3]. This offers a good opportunity to investigate whether prior experience influences ICT students' motivation and dropout.

The students who have learned programming before starting ICT studies at the higher education level have learned it independently or at the general education level. This could give them an advantage while studying ICT at university [4], as knowledge a person has gained from past behavior will help him/her to form intention [24]. In Estonia, ICT is applied at the general school level in both formal and informal education, but not systematically. In most schools, there are separate lessons for learning ICT, but there is high variation in the grades in which these lessons are provided and in the content of the programs. Some schools teach how to use text editor and presentation programs, some teach how to create webpages and some introduce programming. In the current study, students who have and students who have not learned programming before university are under investigation to find out if prior experience in programming influences their motivation and gives them an advantage in ICT studies.

In a previous study in Estonia it was found that $8 \%$ of ICT students were already working in the ICT field when they entered a higher education institution and that the main reasons for working were financial situation and gaining work experience, which is important in the labor market [3]. Working during studies is an important factor determining students' dropout at least in some other fields (doctoral studies in education), since it is difficult to combine studies with work [25]. Based on prior students, the number of working ICT students is growing every year, so that even more students are working during the second and third study-year. A prior study with ICT students showed that already at the beginning of their studies, students considered working - the students' perception about the mean probability of going to work while studying was around $57.7 \%$ in Estonia [3]. Moreover, a study about students in different disciplines in higher education has shown that working during the final year of studies increases the probability of finding a full-time job after graduation [26]. Thus, working during studies could be positive.

However, higher occupational and family responsibilities could also be related to dropout - this has been found in the case of doctoral students in education [25]. The more hours a week students work, the higher the dropout rate [26]. In the context of different disciplines in higher education, Polidano and Zakirova [26] found that working 16-24 hours a week during studies reduced course completion rate by $8 \%$ and working more than 24 hours a week reduced it by $14 \%$. Preventing dropout is becoming increasingly important, since a higher education degree is valued in the ICT sector. A study carried out in the USA (2000-2005) showed that the importance of a Bachelor's or higher degree in most ICT occupations had grown [27]. Also, employees with higher education earned more within the same occupation [27]. So, it is more beneficial for students if they finish their studies in ICT. It would be interesting to know if experience of working during studies influences ICT students' motivation to learn.

Based on the above, the following research questions were formulated for this study: 1) "Which differences appear in the motivation of ICT students who have and who do not have prior experience in programming?" and 2) "Which differences appear in the motivation of ICT students who work and who do not work in the ICT field while studying?"

\section{METHODS}

Data was collected after the first semester in school year 2013/2014 from 301 first year students who started their studies in ICT related curricula. $72 \%$ of the students were male and $28 \%$ female - this is similar to the gender distribution in the ICT studies in Estonia, where about $25 \%$ of the students are female. They started their studies in Estonia at three higher education institutions and in eight different curricula: Computer Science and Computer Engineering curricula at the University of Tartu; Computer and Systems Engineering, Business Information Technology and Informatics at the Tallinn University of Technology; and IT Systems Administration, IT Systems Development, and Information System Analysis at the Estonian Information Technology College. Together, these three higher education institutions graduate the vast majority of ICT students in Estonia.

Data about the students' motivation was collected with Academic Motivation Scale (AMS-C 28) College (CEGEP) version [28]. The scale contained 28 items and the students were asked to indicate to what extent each of the items corresponded to the reasons why they started higher education 
studies. They assessed the items on a 7-point Likert scale: 1 does not correspond at all; 2 - rather does not correspond; 3 corresponds a little; 4 - corresponds moderately; 5 - rather corresponds; 6 - corresponds a lot; 7 - corresponds exactly. The scale helps to determine 7 constructs of motivation. Intrinsic and extrinsic motivation are both divided into three subcategories, amotivation being the seventh category [28]. Intrinsic motivation is divided into intrinsic motivation to know, intrinsic motivation toward accomplishment, intrinsic motivation to experience stimulation. Extrinsic motivation is divided into identified extrinsic motivation, introjected extrinsic motivation and external regulation. In Table I, these seven motivation types have been explained. The Academic Motivation Scale was selected for the current study because it had been validated in former studies [29].

TABLE I: SEVEN MOTIVATION TYPES (BASED ON [13], [16], [17])

\begin{tabular}{|c|c|c|}
\hline \multicolumn{2}{|c|}{ Motivation type } & Explanation \\
\hline \multirow[t]{3}{*}{$\begin{array}{l}\text { Intrinsic } \\
\text { motivation }\end{array}$} & to know & $\begin{array}{l}\text { person wishes to learn and get } \\
\text { new knowledge }\end{array}$ \\
\hline & $\begin{array}{l}\text { toward } \\
\text { accomplishment }\end{array}$ & $\begin{array}{l}\text { person wishes to accomplish } \\
\text { something }\end{array}$ \\
\hline & $\begin{array}{l}\text { to experience } \\
\text { stimulation }\end{array}$ & $\begin{array}{l}\text { person does something because } \\
\text { it is satisfying and gives a good } \\
\text { feeling }\end{array}$ \\
\hline \multirow[t]{3}{*}{$\begin{array}{l}\text { Extrinsic } \\
\text { motivation }\end{array}$} & identified & $\begin{array}{l}\text { person accepts the regulation } \\
\text { because the activity is judged } \\
\text { as valuable/useful and fits their } \\
\text { value system }\end{array}$ \\
\hline & introjected & $\begin{array}{l}\text { person performs an action out } \\
\text { of obligation to avoid anxiety, } \\
\text { shame, and pressure }\end{array}$ \\
\hline & external regulation & $\begin{array}{l}\text { person acts to satisfy an } \\
\text { external demand or obtain an } \\
\text { external reward contingency, } \\
\text { the locus of control is purely } \\
\text { external }\end{array}$ \\
\hline Amotivatio & & person has a lack of motivation \\
\hline
\end{tabular}

Data about prior programming experience and work and study experience were collected using a questionnaire, which was filled in by the students during their courses. Thus, the students who were not attending the face-to-face studies could not fill in the questionnaire. The possibility of responding to the questionnaire electronically was offered to these students, but this option was used rather seldom. The total number of ICT students in the three higher education institutions where the data was collected was 783, of whom 301 filled in the questionnaire both on paper or electronically. First, some background information was collected (e.g., gender, age). In the main part of the questionnaire, the following questions were asked concerning this study (some more questions that are not analyzed in the current study were asked): 1) "How complicated are your university studies compared to high school studies?" (answers were given on a 5-point Likert scale: 1 - much easier, 2 - easier, 3 - more or less the same, 4 - more complicated, 5 - much more complicated); 2) "How high is the probability that you will start working during studies?" (an open-ended numerical answer was expected, answers were divided into five categories: <20\%, 21-40\%, 41-60\%, $61-80 \%,>80 \%$ ); 3) "How well does the curriculum in which you are studying meet your expectations?" (answers were given on a 5-point Likert scale: 1 - very poorly, 2 - poorly, 3 - fairly, 4 - well, 5 - very well); 4) "How well do lecturers and their teaching methods meet your expectations?" (answers were given on a 5-point Likert scale: 1 - very poorly, 2 poorly, 3 - fairly, 4 - well, 5 - very well); 5) "How balanced are theoretical knowledge and practical skills in your studies?" (answers were given on a 3-point scale: 1 theoretical knowledge dominates, 2 - theoretical knowledge and practical skills are in balance, 3 - practical skills dominate). T-test was used to find out whether students with prior programming experience had differences in their motivation to learn. T-test was also used to establish whether there were any differences in the motivation of the students who were currently working and those who were not working.

\section{RESUltS AND DiscUSSION}

\section{A. Programming Experience}

The first research question was "Which differences appear in the motivation of ICT students who have and who do not have prior experience in programming?" The students were divided into two groups: those who had learned programming before entering university $(44.3 \%)$ and those who started learning programming for the first time at university (55.7\%). The students who had learned programming before university started it when they were an average of 16.6 years of age and were an average of 19.9 years of age at the beginning of their studies; $70.4 \%$ of them were male and $29.6 \%$ female. The students who started learning programming for the first time at university were an average of 20 years of age; $73.8 \%$ of them were male and $26.2 \%$ female. Thus, there were no significant differences in the age of these two groups.

A statistically significant difference was found in the motivation of the students who had and of those who did not have experience in programming. The t-test revealed a difference in one extrinsic motivation subcategory - external regulation $(t=2.662, p<0.01)$. The students who started studying programming for the first time at university were more driven by external regulation than the students who had learned programming before entering university (the mean of the first group was 5.62; the mean of the second group was 5.25). This shows that the students who had not learned programming before university more often learned ICT at the higher education level in order to get some kind of external reward. External regulation in ICT studies may mean that students could be highly motivated by a good job in the future, a good salary or good education. However, the reasons have to be clarified in further studies.

The t-test also showed a statistically significant difference between the weighted average grades of the students who had learned programming before university and of those who had not $(t=-2.636$ and $p<0.01)$. The information about the weighted average grade was available only for 143 students and this analysis is made on a smaller sample. $73 \%$ of the students (104 students) were male and 27\% (39 students) female; $42 \%$ (60 students) had prior experience in programming and $8 \%$ (12 students) were working. The students who had learned programming had higher weighted average grades (grades and credit points that each course gave were taken into account - the higher the amount of credit points earned the more this particular grade was taken into 
account in calculating the average) in the first semester. The mean weighted average grade of the students who had learned programming before was 3.56 and the mean of the students who started learning programming at university was 3.21 (the maximum weighted average grade was 5 - the grades were based on the percentage of the course outcome, not a certain percentage of the number of students). These findings suggest that if a student had learned programming before university, he/she was at an advantage compared to a student who had the first contact with programming at university. Moreover, according to the literature review, the academic performance in the first year may be related to future dropout [30]. Longitudinal study is needed to find out if the students who had a low weighted average grade in the first semester would also drop out with higher probability in their following studies.

The students who had learned programming before entering university evaluated the studies at the university to be easier than the students who started learning programming at university $(p<0.05)$. During the first semester, the students had to pass difficult subjects, such as mathematics [18] and programming [19], although eight different curricula were under investigation and the courses and the volume of the courses varied in these curricula. At the Estonian Information Technology College, first-semester students from all three curricula (IT Systems Administration, IT Systems Development, Information System Analysis) have to pass the course Introduction to Programming in Java, which gives them 6 credit points; at the University of Tartu, students from Computer Engineering and Computer Science curricula have to pass the course Computer Programming (6 credit point); at the Tallinn University of Technology, students from Computer and Systems Engineering curriculum have to pass Programming I (5 credit points); students from Informatics curriculum have to pass the Introduction to Programming course (4 credit points) and students from the Business Information Technology curriculum do not start studying programming before the second semester. There are also differences in mathematics courses: during the first semester, students from all three curricula at the Estonian Information Technology College have to pass the Pre-Sessional Course of Mathematics (2 credit points) and the course Mathematical Analysis (4 credit points); at the University of Tartu, students from Computer Engineering and Computer Science curriculum have to pass the courses Elements of Discrete Mathematics (6 credit points), Higher Mathematics (6 credit points) and Elementary Mathematics (3 credit points); at the same university, students from Informatics curriculum have to pass the courses Elements of Discrete Mathematics (6 credit points) and Elementary Mathematics I (6 credit points); students from all three curricula at the Tallinn University of Technology have to pass the courses Mathematical Analysis I ( 5 credit points) and Discrete Mathematics (6 credit points). If the subjects are too difficult, it may cause lower motivation and dropout. The students' answers are shown in Fig. 1. The mean score of the students who started learning programming at university was 2.99 and the mean of the students who had learned programming before was 3.39. Prior experience in programming seems to give students an advantage at least in the first semester compared to other students. These results are similar to the result of Hagan and Markham [4], who found, in addition to the difference between experienced and inexperienced students, that the difference was also related to the level of experience - the number of programming languages the person had studied.

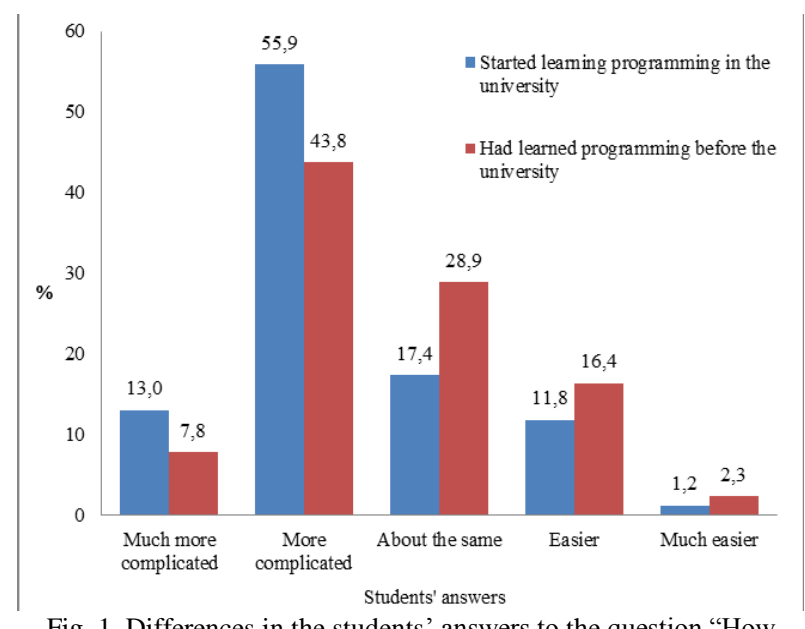

Fig. 1. Differences in the students' answers to the question "How complicated are your university studies compared to high school studies?"

The results suggest that before starting studies at the higher education level, young people should have more possibilities to study programming. Further investigation is needed to find out if students also have an advantage during the next semesters or if they are only at an advantage as long as other students have not learned programming.

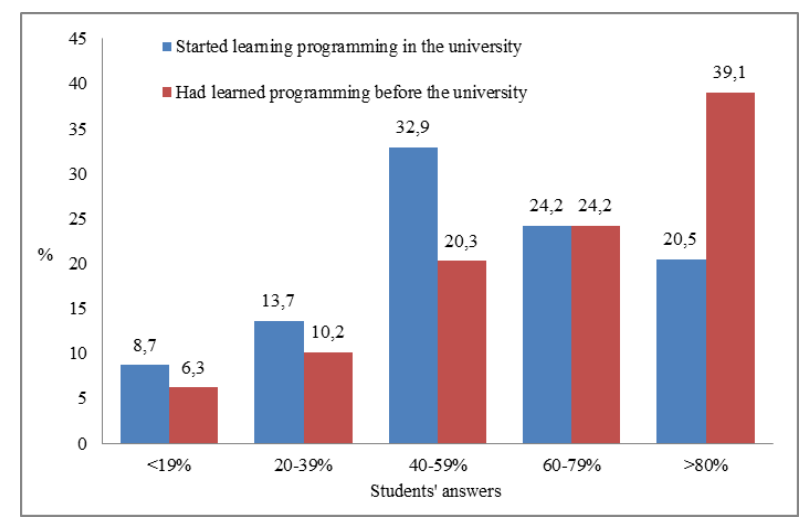

Fig. 2. Differences in the students' answers to the question "How high is the probability that you will start working during studies?"

Students were also asked how high they thought was the probability that they would start working during studies. A statistically significant difference was found between the students who started learning programming at university and the students who had learned it before $(p<0.05)$. The results are shown in Fig. 2. While $20.5 \%$ of the students who started learning programming at university responded that the probability of starting working during studies was $80 \%$ and higher, the same answer was given by $39.1 \%$ of the students who had learned programming before university. Most of the students who started studying programming at university (32.9\%) answered that the probability of working during studies was between $40 \%$ and $59 \%$, so they considered working but were not as sure as the students who had learned programming before. When a student starts working, his/her occupational responsibilities grow, which may cause dropout [25]. This could be a problem, as higher education is needed 
in the ICT labor market [27]. However, there may be people who can manage studies and working very well and activities at work could even support their studies.

\section{B. Work Experience}

The second research question was "Which differences appear in the motivation of ICT students who work and of those who do not work in the ICT field while studying?" About 6\% (18 students out of 301) of the first-year students who answered the questionnaire were already working in the ICT field. This is a small number of students and, at the beginning of studies, it is expected to be small. The working students were an average of 22.2 years of age; 3 of them (17\%) were female and $15(83 \%)$ male. The t-test showed some differences between the motivation of the students who were working and the students who were not working. The results of all motivation types are shown in Table II. Interestingly, working students had higher results in amotivation $(t=2.623$; $p<0.01$ ). The mean of working students was 2.44 and that of non-working students 1.78. So, the students who were working in the ICT field had less motivation to study ICT than the students who were not working. The reason for it could be that higher education studies do not correspond well to the perceptible needs that derive from work experience; however, this needs to be clarified in further studies. Indeed, lack of motivation may cause dropout. Vallerand and Bissonnette [7] found that students who had a higher score in amotivation dropped out with higher probability. During the next study-years, more students would probably start working, as most of the students were considering it already at the beginning of their studies [3]. It could be interesting to investigate if working will decrease their motivation to study (if their amotivation score will increase). Moreover, it would be interesting to find out whether students who are working and have more amotivation at the current point of time drop out in the later stage of their studies.

Also, working students had lower scores in two subcategories of extrinsic motivation: introjected $(t=-2.467$; $p<0.05)$ and external regulation $(t=-2.359 ; p<0.05)$. The mean score of working students' extrinsic introjected motivation was 3.78 and the mean score of non-working students was 4.69. Introjected motivation means that students are doing something to avoid negative emotions, such as anxiety, shame, and pressure [13]. The mean score of working students' external regulation was 4.83 , whereas the mean score of non-working students was 5.50. This difference is similar to the difference between the students who had learned programming before university and the students who had not. So, prior experience in programming and working during studies seems to decrease the external regulation. Still, the third type of extrinsic motivation - identified motivation was at the same level in the case of both working and non-working students.

Although differences were found in working and non-working students' extrinsic motivation, no statistically significant differences were detected in their intrinsic motivation, which influences students' academic achievement [14]. However, working students had slightly higher scores in intrinsic motivation - to know and intrinsic motivation - to experience stimulation (Table II). Non-working students had higher results in intrinsic motivation - toward accomplishment. This needs further investigation, as differences may appear on a bigger sample or during the next semesters.

TABLE II: COMPARISON OF MOTIVATION TYPES BETWEEN THE STUDENTS WHO WORK IN THE ICT FIELD AND THOSE WHO DO NOT WORK IN THE ICT

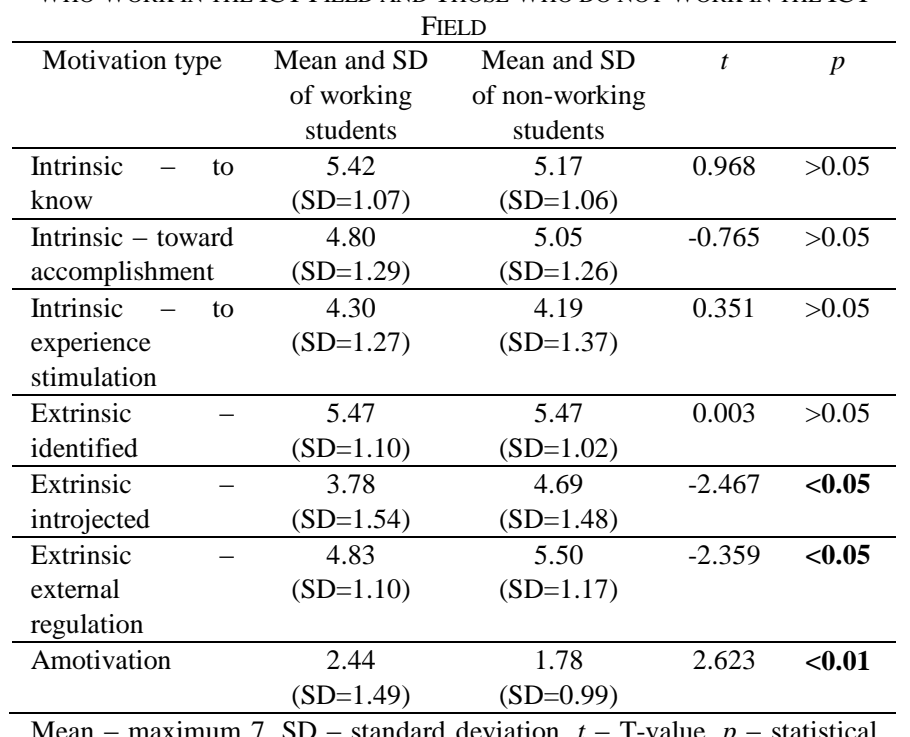

Mean - maximum 7, SD - standard deviation, $t-$ T-value, $p$ - statistical significance of the difference of two means.

A statistically significant difference was found between working and non-working students and how well the curriculum in which they were studying met their expectations. The students who were working in the ICT field felt that the curriculum met their expectations less than the non-working students $(t=-3.117 ; p<0.01)$. The mean score of the working students was 3.11, whereas that of the non-working students was 3.64. Interestingly, there was no statistically significant difference in how the lecturers and their teaching methods met the students' expectations and how well they thought the practice and theory were balanced in their studies. This means that the difference was related to the curriculum, not the lecturers, learning methods or balance between practice and theory. This could be because during the first semester, the working students did not learn the things they needed in their everyday work. However, there is no information about what the students did at work. There might have been some students whose studies supported their work. The group of working students needs further investigation to find out what they expect from their studies, what their employer expects and which are the skills and knowledge they need at work. Also, the working students may need more flexible learning opportunities [25]. While developing ICT related curricula, it should be considered that many students are working and their studies should support their work. There might be a need for a wider range of different curricula or curricula which are more flexible and in which students can choose between different courses.

\section{CONCLUSION}

A high dropout rate among ICT students is a big problem in many countries. Motivation is one of the characteristics which influence how students approach their learning [10] and is important in academic achievement [11]. Motivation could be 
influenced by prior experience [4], such as learning ICT at the general education level and working in the ICT field.

Some differences were found in the motivation of students who had and those who did not have experience in programming. The students who started learning ICT at university had more external regulation leading their motivation than the students who started learning programming before university. It was found that those who had prior experience in programming were at an advantage, reflected in the weighted average grade in the first semester, when compared to the students who started learning programming at university. This suggests that before starting studies at the higher education level, young people should have more possibilities to study programming. This opportunity could be part of general education. Further investigation is needed to find out if they continue to have an advantage during the next semesters or if they are only at an advantage as long as other students have not learned programming. However, the students who had learned programming thought that the probability of them starting working during studies was higher and that working and studying at the same time could be difficult. Working students need more flexible learning opportunities [25].

Some differences were also found in the motivation of working and non-working students. Working students had higher scores in amotivation - this means that they were less motivated to study. In addition, working students had lower scores in two types of extrinsic motivation - introjected and external regulation - than non-working students. Working students had less extrinsic motivation, but no statistically significant differences were found in the case of intrinsic motivation. Also, it was revealed that working students felt that the curriculum in which they were studying met their expectations less compared with the non-working students. This could be because they did not study the things they needed in their everyday work. However, in this study, only $6 \%$ of the first-year students were working in the ICT field, so the two groups were uneven in size. More of them will probably start working during the following study-years. So, these preliminary findings will need further investigation when more students will have started working.

In conclusion, it is clear that ICT students have different backgrounds and experiences that influence their motivation and learning outcomes. Experience is an influencing factor in ICT studies and universities should take it into account when developing ICT related curricula, as well as in supporting learners to avoid dropout and ensure smooth progress according to the needs of the labor market.

\section{ACKNOWLEDGMENT}

This research was supported by the European Union through the European Regional Development Fund. It is financed in the project "Conceptual Framework for Increasing Society's Commitment in ICT: Approaches in General and Higher Education for Motivating ICT-Related Career Choices and Improving Competences for Applying and Developing ICT."

\section{REFERENCES}

[1] T. Hüsing et al. (2013). E-leadership, e-skills for competitiveness and innovation vision, roadmap and foresight scenarios final report.
[Online].

Available: http://ec.europa.eu/enterprise/sectors/ict/files/eskills/vision_final_rep ort_en.pdf

[2] A. Jürgenson, E. Mägi, K. Pihor, V. Batueva, H. Rozeik, and H. Arukaevu. (2013). Eesti IKT kompetentsidega tööjõu hetkeseisu ja vajaduse kaardistamine. Praxis. [Online]. Available: http://www.kutsekoda.ee/fwk/contenthelper/10373139/10493920/IK T_uuringu_16pparuanne.pdf

[3] K. Kori, M. Pedaste et al., "Why do students choose to study information and communications technology?" The European Procedia Social and Behavioral Sciences, Elsevier, 2014.

[4] H. Hagan and S. Markham, "Does it help to have some programming experience before beginning a computing degree program?" in Proc. the 5th Annual SIGCSE/SIGCUE ITiCSE Conference on Innovation and Technology in Computer Science Education, 2000, pp. 25-28.

[5] F. Weng, F. Cheong, and C. Cheong, "The combined effect of self-efficacy and academic integration on higher education students studying IT majors in Taiwan," Education and Information Technologies, vol. 15, pp. 333-353, 2010.

[6] J. O. Talton, D. L. Peterson, S. Kamin, D. Israel, and J. Al-Muhtadi, "Scavenger hunt: Computer science retention through orientation," in Proc. the 37th SIGCSE Technical Symposium on Computer Science Education, pp. 443-447, 2006.

[7] R. J. Vallerand and R. Bissonnette, "On the predictive effect of intrinsic, extrinsic, and amotivation styles on behaviour: A prospective study," Journal of Personality, vol. 60, pp. 599-620, 1992.

[8] R. W. Rumberger, "Why students drop out of school," in G. Orfield, Ed., Dropouts in America: Confronting the Graduation Rate Crisis, Cambridge, MA: Harvard Education Press, 2004, pp. 131-155.

[9] P. Kleinginna and A. Kleinginna, "A categorized list of motivation definitions, with suggestions for a consensual definition," Motivation and Emotion, vol. 5, no. 4, pp. 263-291, 1981.

[10] N. Entwistle, "Concepts and conceptual frameworks underpinning the ETL project,” Occasional Report 3, Edinburgh, Scotland: ETL Project, 2003.

[11] M. Bruinsma, "Motivation, cognitive processing and achievement in higher education," Learning and Instruction, vol. 14, no. 6, pp. 549-568, 2004.

[12] A. E. Gottfried, "Commentary: The role of environment in contextual and social influences on motivation: Generalities, specificities and causality," in K. R. Wentzel and A. Wigfield, Eds., Handbook of Motivation at School, New York: Routledge, pp. 462-475, 2009.

[13] E. L. Deci and R. M. Ryan, Intrinsic Motivation and Self-Determination in Human Behavior, New York: Plenum, 1985.

[14] R. M. Gottfried, "Academic motivation in elementary and junior high school students," Journal of Educational Psychology, vol. 77, no. 6, pp. 631-645, 1985.

[15] B. Abar, C. C. Abar, M. Lippold, C. J. Powers, and A. E. Manning, "Associations between reasons to attend and late high school dropout," Learning and Individual Differences, vol. 22, pp. 856-861, 2012.

[16] R. M. Ryan and E. L. Deci, "Intrinsic and extrinsic motivations: classic definitions and new directions," Contemporary Educational Psychology, vol. 25, pp. 54-67, 2000.

[17] E. L. Deci, Intrinsic Motivation, New York: Plenum, 1975

[18] B. Divjak, M. Ostroski, and V. V. Hains, "Sustainable student retention and gender issues in mathematics for ICT study," International Journal of Mathematical Education in Science and Technology, vol. 41, no. 3, pp. 293-310, 2010.

[19] J. Bennedsen and M. E. Caspersen, "Failure rates in introductory programming," The SIGCSE Bulletin, vol. 39, no. 2, pp. 32-36, 2007.

[20] I. Miliszewska and G. Tan, "Befriending computer programming: A proposed approach to teaching introductory programming," Informing Science and Information Technology, vol. 4, 2007, pp. 277-289.

[21] C. Watson and F. W. B. Li, "Failure rates in introductory programming revisited," in Proc. the 2014 Conference on Innovation \& Technology in Computer Science Education, 2014, pp. 39-44.

[22] L. J. Baker, C. McDowell, and K. Kalahar, "Exploring factors that influence computer science introductory course students to persist in the major," in Proc. the 40th ACM Technical Symposium on Computer Science Education, 2009, pp. 153-157.

[23] T.-S. Fan and Y. C. Li, "Gender issues and computers: College computer science education in Taiwan," Computers \& Education, vol. 44, pp. 285-300, 2005.

[24] M. Fishbein and I. Ajzen, Belief, Attitude, Intention and Behavior: An Introduction to Theory and Research, Reading, MA: Addison-Wesley, 1975.

[25] A. Ots, Ä. Leijen, and M. Pedaste, "Relationship between doctoral students' proceeding in studies and coping with occupational and 
family responsibilities," in Lifelong Learning, J. Mikk, P. Luik, and M. Veisson, Eds., 2012, pp. 130-145.

[26] C. Polidano and R. Zakirova, Outcomes from Combining Work and Tertiary Study, National Centre for Vocational Education Research, 2011.

[27] A. Sum, I. Khatiwada, and S. Palma, "Employment prospects in information technology jobs for non-college-educated adults," Challenge, vol. 50, no. 1, pp. 97-114, 2007.

[28] R. J. Vallerand, M. R. Blais, N. M. Brière, and L. G. Pelletier, "Construction et validation de l'Échelle de Motivation en Éducation (EME)," Revue Canadienne des Sciences du Comportement, vol. 21, pp. 323-349, 1989.

[29] A. Fairchild, S. J. Horst, S. J. Finney, and K. E. Barron, "Evaluating existing and new validity evidence for the academic motivation scale," Contemporary Educational Psychology, vol. 30, pp. 331-358, 2007.

[30] J. Allen, S. B. Robbins, A. Casillas, and I. S. Oh, "Third-year college retention and transfer: Effects of academic performance, motivation, and social connectedness," Research in Higher Education, vol. 49, pp. 647- 664, 2008.

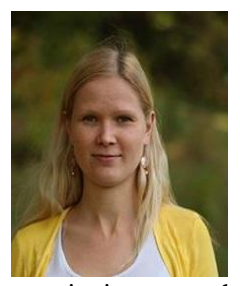

Külli Kori was born in Türi, Estonia, in 1989. She received her bachelor of science degree in 2011 and master of arts degree in education (biology teacher) in 2013 from the University of Tartu, Estonia. Currently, she is a doctoral student in educational sciences at the University of Tartu, Estonia (since 2013).

She started working as a specialist for technology education in 2013. Since 2014, she has been working as a junior research fellow of educational technology at the University of Tartu. Her research interests are in how to motivate career choices in ICT and how to support ICT students.

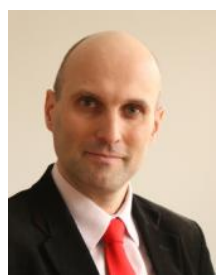

Margus Pedaste was born in Tartu, Estonia, in 1976. $\mathrm{He}$ is a full professor of technology education at the University of Tartu, where he is leading the Centre for Educational Technology and Pedagogicum of the university (consortium for coordinating teacher education and related research).

$\mathrm{He}$ has worked as a part time science teacher in a general school for 15 years. He is also a developer of the Estonian biology curriculum for general schools and has been the president of the Association of Estonian Biology Educators. Prof. Pedaste received his $\mathrm{PhD}$ degree on the theme "Problem solving in web-based learning environments". He is also the main developer of the web-based learning environments "Hiking across Estonia", "Young Scientist" and "Young Researcher", which are created for developing students' skills of problem solving and inquiry learning.
Prof. Pedaste has been involved in the EC FP6 project VOLVOX, EC FP6 project BIOHEAD-CITIZEN, EC FP7 project SCY, and is currently leading the EC FP7 project Go-Lab within the University of Tartu and internationally coordinating the EC FP7 project Ark of Inquiry. He has also been the coordinator of the large-scale European Social Foundation project EDUKO for developing teacher education and related staff at the University of Tartu.

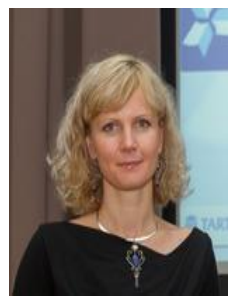

Äli Leijen was born in Tartu, Estonia, in 1979. Her academic background is educational sciences (bachelor's degree from the University of Tartu, Estonia in 2001, master of science degree from the University of Twente, Netherlands, in 2004). Her PhD thesis, "The reflective dancer: ICT support for practical training" (University of Utrecht, Netherlands, 2008), was explored possibilities for innovation and change in arts education.

She is currently working as a senior research fellow at the University of Tartu in Estonia. Her current work is mostly focused on teacher education. Her current research themes include supporting students' reflection; development of professional identity; and ICT as a means for supporting pedagogy and implementing innovations. She has worked in several national and international research projects.

Dr. Leijen is a member of several international research associations, such as EARLI, AERA, and ISATT. In 2014, she received "The Best Publication in Estonian in the Field Educational Sciences" award from the Ministry of Education for the special issue of the Estonian Journal of Education: "Teacher education and university teaching". She was the lead editor and co-author of this publication. In 2011, she received the best paper award by the IADIS (International Association for Development of the Information Society) International Conference Committee at CELDA (Cognition and Exploratory Learning in Digital Age) conference.

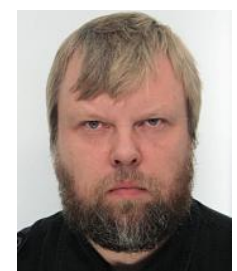

Eno Tõnisson was born in Tartu, Estonia, in 1969. He graduated as a mathematics teacher in 1992 and received his master of science degree in mathematics in 1996 from the University of Tartu. His current research themes include use of computer algebra systems in mathematics education; didactics of programming; career choices of students of computer science and information technology.

He has worked as a mathematics teacher of secondary school for 8 years. Mr. Tõnisson started working at the University of Tartu as an assistant of didactics of mathematics in 1994. Since 2001, he has been working as a lecturer in the Institute of Computer Science of the University of Tartu. 